\title{
REGULAÇÃo SANITÁRIA SEM FRONTEIRAS ${ }^{*}$
}

\author{
SANITARY REGULATION WITHOUT BORDERS
}

Cláudio Maierovitch Pessanha Henriques ${ }^{(*)}$

\section{RESUMO}

Diversas condições e variáveis interferem na ocorrência de doenças transmissiveis, entre elas o tamanho da população, a aglomeração, a probabilidade de transmissão. A história assistiu à dinâmica das moléstias transmissíveis. O contato com outras populações e o transporte de mercadorias levou à noção de vigilância sanitária de fronteira e a certas práticas sanitárias.

O direito que evoluiu com relação a estas práticas é o Direito Sanitário internacional, que lida com interesses de proteção da população e interesses do coméncio e intercâmbio. As fontes deste direito são os tratados, as convençōes os atos jurídicos emanados das organizações sanitárias internacionais, o caso da OMS. O Brasil adotou o Regulamento Sanitário Internacional, o qual deve estar coadunado com os direitos individuais e coletivos.

A aplicação deste regulamento tenta coordenar-se com o livre trânsito comercial. Afora as fontes provenientes das organizaçōes sanitárias, temos dispositivos de regulamentação do trabalho, meio ambiente, navegação, cujas competências e responsabilidades variam conforme o enquadramento.

O mundo conta hoje com organizações de blocos regionais, a dimensão e a complexidade crescentes exigem uma mudança de enfoque da segurança sanitária no panorama mundial, levando em conta que os países em desenvolvimento merecem atenção especial. Conclui-se que a grande ameaça sanitária é a diferença entre os povos.

(*) Extraido e adaptado de HENRIQUES, C. M.P. "A Vigilância Sanitária dos Portos: Experiência da prevençāo à entrada da cólera no porto de Santos". Dissertação de Mestrado. Departamento de Medicina Preventiva da Faculdade de Medicina da Universidade de Sāo Paulo, 1992.

${ }^{(*)}$ Médico sanitarista do Instituto de Saúde da Secretaria de Estado da Saúde - SP. Diretor adjunto de serviços e correlatos - Agência Nacional de Vigilância Sanitária- Ministério da Saúde - Brasil. 


\section{Palavras-chave}

Vigilância Sanitária, Organização Mundial De Saúde, Fronteiras, Desigualdade, Direito Internacional.

\section{ABSTRACT}

Several conditions and elements interfere in the occurrence of transmissible diseases, among them the size of the population, the gathering, the transmission probability. History has witnessed the dynamics of transmissible diseases. The contact with other populations and the transportation of goods brought the need of sanitary surveillance of state borders and the regulation of sanitary practices.

International Sanitary Law has developed from these practices, regulating health protection of populations and facing interests of trade and exchanges as well as the laws of free trade. The legal sources of the International Sanitary Law are the international agreements, conventions and enacted resolutions and acts of the international sanitary organizations, specially WHO - World Health Organization. Brazil has adopted the International Sanitary Regulation, which is to be adjusted to fundamental individual and collective rights. Apart from the normative acts of the global and regional sanitary organizations, regulatory acts in labour, environment, navigation, coming from and being enforced by different international organizations also intersect the International Sanitary Law.

The growing complexity and dimension of the organization of countries in regional blocks demands a global change in sanitary security practices, with special attention to developing countries, as the difference among countries is a main sanitary threat.

\section{Key words}

Sanitary Surveillance, Health, Borders, Inequality, International Law, International Sanitary Law, World Health Organization.

A ocorrência das doenças transmissíveis, como o próprio nome expressa, tem como elemento essencial o contato entre agente infeccioso ou seu subproduto e o potencial doente, chamado hospedeiro. Isso pode acontecer de várias formas, variando conforme a doença; diretamente de uma pessoa a outra, pelo consumo de alimentos, por contaminação ambiental, por vetores etc. O tamanho da população reunida em uma localidade é fator importante para que haja exposição ao agente. A aglomeração, ao lado de más condições de vida, faż crescer a possibilidade desse encontro.

No entanto, não basta o contato, para haver doença é preciso que haja susceptibilidade. Muitas doenças geram imunidade duradoura após a primeira infecção em um indivíduo, de forma que elas podem deixar de acontecer numa comunidade se uma proporção suficientemente grande de pessoas tiver sido acometida. O mesmo pode ocorrer se for conferida imunidade artificialmente, com a administração de vacinas. Nessa situação, diz-se, no 
jargão da epidemiologia, que esgotou-se o "estoque de susceptiveis", que é reposto com a entrada de pessoas que não tiveram a infecção anteriormente, incluindo as crianças que nascem ou que perderam a imunidade. Uma vez que o "estoque" seja suficientemente grande e existindo o contato com o agente infeccioso, a doença volta a manifestar-se naquela comunidade. ${ }^{(1)}$

Adotando um raciocínio bastante simplificado, o comportamento de uma enfermidade transmissivel em determinada população ${ }^{(2)}$ depende de variáveis, como a infectividade, a probabilidade de transmissão, os padrões de contato, o número reprodutivo básico ${ }^{(3)}$, o tamanho da populaçăo, os nascimentos e óbitos. Exemplificamos com o sarampo, que só existe em uma comunidade se ela for suficientemente numerosa ${ }^{(4)}$ para que o vírus continue circulando entre os susceptíveis à medida que individuos infectados recuperam-se e tornam-se imunes.

Assim, a dinâmica das moléstias transmissiveis transformou-se enormemente ao longo da história com o surgimento das cidades e a urbanização crescente da população. Seguindo as rotas de mercadorias e dos meios de transporte, entre as primeiras cidades importantes destacavam-se aquelas que abrigavam portos de navegação marítima.

A propagação das doenças de um canto a outro do mundo e as tentativas de bloqueá-las quase sempre deram destaque ao transporte marítimo, ainda hoje o principal meio de transporte de bens por longas distâncias.

Os navios, além das mercadorias, carregam, em uma relação quase orgânica, os tripulantes responsáveis pela sua operação, água e alimentos necessários à manutenção dessas pessoas, dejetos de seu metabolismo, roedores, insetos, todos capazes de portar ou transmitir doenças, visivelmente para a consciência empírica que gerou as primeiras ações, legitimada pelas demonstrações da microbiologia, desde que se afirma como teoria científica no século $X I X^{(5)}$.

A vigilância de fronteiras encontra-se, ainda hoje, entre as práticas sanitárias mais apegadas à noção de contagionismo ${ }^{(6)}$, herdeira do controle da

(1) MCNEIL, W. H. "Plagues and People", New York: Anchor Books, 1989, pp. 43-45.

(2) HALLORAN, M. E. "Concepts of Infectious Disease Epidemiology", in ROTHMAN. K. J. Modern Epidemiology. Philadelphia, PA: Lippincot-Raven Publishers, 1998, pp. 529-545.

(3) Entendido como o número esperado de novos hospedeiros infectantes que cada hospedeiro infectante produzirá durante seu periodo de infectividade, em uma população grande e completamente susceptivel, não incluindo os casos secundários, cf. HALLORAN, M. E. "Concepts of Infections...", cit., pp. 536-537.

(4) Chamado tamanho crítico da população. Para o sarampo, admite-se o mínimo de 500 mil pessoas, cf. FINE, P. E. M. "Introduction to the Epidemiology of Infections", in Epidemiology and Control of Communicable Diseases. Londres, 1998 (Apostila do Curso de Pós-graduação da London School of Hygiene and Tropical Medicine).

(5) BERLINGUER, G. "A Doença". São Paulo: Hucitec.1988, pp. 76-77.

(6) Nos termos em que utiliza AYRES, J. R. C. M. "A Epidemiologia e o Projeto Emancipador nas Práticas de Saúde: A Critica da Razão Instrumental na Constituiçāo Histórica da Ciência Epidemiológica". São Paulo, 1991. Dissertação de Mestrado. Faculdade de Medicina da Universidade de São Paulo, p. 204 
circulação de produtos e de gente surgido, como a medicina urbana france$\mathrm{sa}^{(7)}$, na condição de um aperfeiçoamento do modelo político-médico da quarentena, realizado no final da Idade Média, nos séculos XVI e XVII.

Textos clássicos deram lugar de destaque às tentativas de conter epidemias através do estabelecimento de barreiras ao trânsito de pessoas, como "A Peste", de Camus's), que constrói em grande parte o ambiente psicológico de sua obra sobre o contexto do isolamento da cidade, visando à circunscrição do mal.

A associação entre doença e transporte marítimo aparece já no relato de Snow sobre o primeiro caso de cólera ocorrido em Londres, em 1848, um marinheiro vindo de Hamburgo, de onde teria trazido a doença. ${ }^{(9)}$ São diversas as referências que ele faz à relação da atividade naval com a transmissão de cólera, bem como à susceptibilidade dos marinheiros à doença em função de seus hábitos. ${ }^{(10)}$

Em nosso país, o receio de doenças como a variola e a febre amarela (ambas provavelmente importadas pela via transoceânica, sendo a segunda atribuída às embarcações negreiras $\left.{ }^{(11)}\right)$ levou a que, com a vinda da Corte para o Rio de Janeiro, entre as primeiras medidas estivesse a criação do "(...) cargo de Provedor-Mor da Saúde, incumbido de fiscalizar o estado de saúde das equipagens das embarcações que viessem de diversos portos, obrigando-as a dar fundo a mais distâncias, a que houvesse saída dos que fossem suspeitos e estabelecer quarentenas (...)". Tal serviço é citado como "(...) a única organização realmente apreciável..., regulado em 1829 e estabelecido no Rio de Janeiro e demais cidades litorâneas".

Fazemos referência a esses antecedentes históricos porque muitos conceitos mudaram pouco na vigilância sanitária de fronteiras e meios de transporte desde os seus primórdios, apegada ao modelo da policia médica e do estabelecimento de barreiras sanitárias para deter a propagação das doenças infecto-contagiosas, sem ter reorientada sua prática na medida da superação das concepções epidemiológicas que lhe deram origem. Isso não é uma completa surpresa, em uma estrutura que atua em território de segurança nacional, oculta das vistas do público-alvo de sua proteção, trabalhando com outro tipo de população que não é diretamente beneficiada. As pressões mais presentes neste campo provavelmente vêm do empresariado interessado, cuja única exigência quanto a seu funcionamento é de que não cause embaraços ao comércio.

(7) FOUCAULT, M. "O Nascimento da Medicina Social", in Microfísica do Poder. Rio de Janeiro: Graal, 1984, p. 89.

(8) CAMUS, A. "A Peste". Rio de Janeiro: Opera Mundi, 1973, pp. 102-264.

(9) SNOW, J. "Sobre a Maneira de Transmissão do Cólera". São Paulo: Hucitec-ABRASCO, 1990, p. 71.

(10) SNOW, J. "Sobre a Maneira...", cit., pp. 74-75, 121, 185, 198.

(11) VIEIRA, F. B. "Primeiros tempos da administração sanitária paulista e seus antecedentes no país", in Arquivos de Higiene e Saúde Pública. São Paulo, 1943, 8(17): 34-7, pp. 35-38. 
Tratando-se de atividade exercida pelo poder público em zona de fronteira, abrangendo ações de controle sobre pessoas, produtos e meios de transporte de vários países, com suas diferentes legislações internas, devemos nos referir ao Direito Internacional Público, e, no seu escopo, ao Direito Sanitário Internacional.

Em sulas origens situam-se as posturas defensivas adotadas em diferentes contextos para tentar bloquear a entrada de epidemias. Relata-se, a título de ilustração, que as quarentenas eram conhecidas desde o século $X V$, quando Veneza tentava impedir a importação da peste, regras que se generalizaram pelos portos cristãos do Mediterrâneo nas décadas seguintes e sobreviveram por cinco séculos até que fossem adotadas as primeiras regras sanitárias gerais. ${ }^{(12)(13)}$ Medidas desta natureza eram tomadas individualmente, conforme as concepçōes sobre a transmissão de doenças em cada época e a proximidade de epidemias que causassem temor, com evidentes prejuizos ao comércio causados pelas barreiras à circulação de mercadorias e viajantes.

Se as medidas de isolamento ou quarentena podiam ser adotadas em momentos de pânico ou submetendo pessoas e povos que não tinham capacidade de afrontá-las, eram inaceitáveis para as atividades com expressão econômica. $O$ início da cooperação internacional na saúde associa-se antes à necessidade de diminuir os obstáculos ao trânsito do que às preocupações com prevenção. A atenção do Direito Internacional para o assunto data da metade do século passado, particularmente quando a epidemia de cólera ameaçava a Europa, criando-se a demanda por acordos que conciliassem os diferentes interesses envolvidos ${ }^{(14)}$.

Por este prisma deve-se entender a realização da $1^{\text {a }}$ Conferência Sanitária Internacional, em Paris, em 1851, seguida por outras oito até o final do século $X I X$, resultando na assinatura dos primeiros tratados ${ }^{(15)}$ e na instituição dos primeiros organismos internacionais para questōes de saúde, ${ }^{(16)}$ até ser constituida a Organização Mundial da Saúde, por decisão de Conferência Internacional realizada em Nova lorque, em 1946, após a Segunda Guerra, em um momento histórico de reorganização dos paises, propicio para o consenso.

(12) MCNEIL, W. H. "Plagues and People", cit., p. 151.

(13) FONSECA. V. S. L. "O Direito Internacional Face a Saúde e as Moléstias Transmissiveis". São Paulo, 1989. Dissertação de Mestrado. Faculdade de Direito da Universidade de São Paulo, p. 87. (14) FONSECA, V. S. L. "O Direito Internacional...", cit., pp. 36-37.

(15) A primeira tentativa de convençāo internacional (equivalente a tratado ou acordo) ocorreu em meio a diferentes posições na primeira Conferência, sendo ratificada por três paises, dois dos quais a denunciaram pouco tempo depois. O primeiro tratado multilateral foi assinado em 1892 com a adesão de 14 Estados europeus e classificava os navios em "indenes, suspeitos ou infectados" quanto ao risco de transmissão de cólera: esta terminologia veio a incorporar-se mais tarde ao Regulamento Sanitário Internacional. FONSECA, V. S. L. "O Direito Internacional...", cit., pp. 89-94 (16) Repartição Sanitária Internacional da América, em 1902; Office Internacional d'Hygiene Publique, em 1907; Repartição Sanitária Panamericana, em 1923. FONSECA, V. S. L. "O Direito Internacional...", cit., pp. 98-100. 
A instância máxima da Organização é sua Assembléia Geral, com atribuição de decidir convenções, regulamentos e recomendações, que, de acordo com a Constituição do organismo, devem ser aprovados por maioria de dois terços, entrando em vigor quando aceitos pelo Estado membro.

A 4롤 Assembléia Mundial de Saúde, realizada em 1951, elaborou o Regulamento Sanitário Internacional, que passou a integrar funcionalmente a própria Constituição da OMS em 1969. Sofreu modificações em 1973, quando se abandonou o Certificado de Vacinação contra Cólera, antes obrigatório, e em 1981, com a exclusão da varíola do texto, dada sua erradicação. 0 Regulamento traz expressa sua finalidade de “(...) conseguir a máxima segurança contra a propagação internacional de enfermidades com um mínimo de entraves para o tráfego mundial"(17). O texto dirige-se com destaque às moléstias transmissiveis quarentenárias ${ }^{(18)}$ e outras que sejam objeto de vigilância internacional tratando quase que exclusivamente da notificação e das normas relativas aos meios de transporte.

Os tratados, as convenções e os atos jurídicos emanados pelas organizações internacionais constituem as fontes do Direito Sanitário Internacional $^{(19)}$. No caso especifico da OMS, os atos jurídicos ${ }^{(20)}$ entram em vigor, de acordo com a Constituição do órgão, em seu art. 22, para todos que não comunicarem recusa, podendo, portanto, tornar-se obrigatórios (exceto as recomendações, é claro) para os Estados independentemente de ratificação. Cabe, por sua vez, a cada Estado integrar as obrigações internacionais à legislação interna(21).

O Brasil depositou sua ratificação na Constituição da OMS em 1948, dando validade interna a tal ato mediante Decreto naquele mesmo ano, sendo adotado aqui o Regulamento Sanitário Internacional em sua integralidade; apenas alguns países manifestaram reservas em relação a certos artigos específicos e um número menor não aderiu a ele..$^{(22)(23)(24)}$

Observe-se que o Regulamento, em muitos artigos, define o máximo que os Estados podem exigir nas situações de sua aplicação, no que é fiel a

(17) "Organizacion Mundial de La Salud", Reglamento Sanitario Internacional. Tercera Edicion Anotada, Art. I. Genebra: OMS, 1983, p. 5.

(18) Adquiriram essa denominação em função das medidas que desencadeavam. Eram: peste, febre amarela, cólera e varíola, que, erradicada, deixou naturalmente de integrar a relação. A Declaraçāo Marítima de Saúde atuatmente inclui, além das três primeiras, tifo exantemático e febre recorrente. DIAS, H. P. "Vigilância Sanitária dos Portos, Fronteiras e Aeroportos. Normas Internas e Internacionais". Brasilia, 1982, pp. 76-82.

(19) Fonte designa a origem dos instrumentos juridicos formais. Adotamos aqui uma terminologia sintética, pois foge aos nossos objetivos um aprofundamento maior. Para uma classificação mais completa ver MELLO, C. D. A. M. "Curso de Direito Internacional Público". 9" ed. Rio de Janeiro: Renovar, 1992, 2 vols., pp. 149-264.

(20) Regulamentos, convenções e recomendações.

(21) Ato que tem sido chamado de internalização.

(22) DIAS, H. P. "Vigilância Sanitária...", cit., pp. 250-251 e 82-97.

(23) FONSECA, V. S. L. "O Direito Internacional...", cit., pp. 30, 75, 104 e 145.

(24) "Organizacion Mundial de La Salud", cit., Reglamento Sanitario Internacional, pp. 58-62. 
suas origens de facilitador dos fluxos internacionais. As reservas a que fizemos menção foram feitas por países - Egito, Índia e Paquistão - que adotaram critérios oficiais mais rígidos.

A lógica do Regulamento - ao definir limites máximos - é diversa daquela da hierarquia da legislação sanitária interna brasileira, em que municípios podem ser mais exigentes que estados e estes mais do que a esfera federal, resguardados os limites de suas competências constitucionais. O terreno é delicado, uma vez que a adoção de determinadas medidas pode estar em confronto com os direitos individuais, como em caso de vacinação ou medicação obrigatória, isolamento, quarentena e outras, em que cabe ao poder público a busca do equilíbrio entre direito individual e coletivo.

O Regulamento é um texto integrado que, em resumo, obriga os países membros a: $:^{(25)}$

1. Comunicar ao Secretariado da OMS os casos de doenças de notificação internacional (atualmente, cólera, peste e febre amarela) e outras informações epidemiológicas de interesse;

2. Oferecer serviços de saúde nos portos e aeroportos de trânsito internacional;

3. Editar documentos internacionais de saúde;

4. Aplicar medidas sanitárias ao tráfego internacional que não sejam mais rigorosas do que aquelas previstas no texto.

Está em andamento sua revisão, prevendo-se que a nova versão não seja oficializada antes de 2002. O comunicado sobre o processo de revisão sublinha preocupações com a aceleração dos meios de transporte, em especial o aéreo, ao lado da ocorrência de doenças infecciosas emergentes e reemergentes em ambientes sob constantes mudanças físicas e sociais ${ }^{(26)}$.

Ao invés de três doenças, passarão a ser notificáveis todos os surtos de doenças ou eventos de caráter urgente e de importância para a saúde pública internacional. Há tendência para substituir o enfoque, dirigido a diagnóstico de doenças, por uma abordagem sindrômica, orientada pela ocorrência de doenças de importância internacional. Além disso, entre as recomendações feitas pelo grupo encarregado pela OMS, cabe citar: deverá ser editado um manual prático para facilitar a aplicação do Regulamento; o texto revisto deverá integrar-se às atividades de vigilância epidemiológica nacionais, regionais e mundial; deverão ser indicadas intervenções consideradas impróprias ou desnecessárias. ${ }^{(27)}$

(25) World Health Organization, Weekly Epidemiological Record, n. 25, 1999, pp. 193-201.

(26) World Health Organization, Forty Eighth World Health Assembly, resolution WHA 48.7, Geneva, 1995.

(27) World Health Organization, Weekly Epidemiological Record, n. 31, 1996, p. 234. 
Diferentemente do atual texto único, a nova versão do Regulamento deverá conter um núcleo principal tratando de obrigações e documentos anexos com recomendações técnicas específicas.

Tais mudanças podem significar um potencial maior de conflito com outras organizações que trabalham para a eliminação de dificuldades para o livre trânsito comercial. No processo, o Secretariado da OMS e os membros do Comitê para Medidas Sanitárias e Fitossanitárias (MSF) da Organização Mundial do Comércio (OMC) vêm buscando compatibilizar a aplicação de medidas contempladas nos documentos de ambos (RSI e MSF), que têm quadros de países membros semelhantes. ${ }^{(28)}$

Além dos documentos citados, da OMS e da OMC, o Codex Alimentarius - estabelecido por comissão conjunta da $\mathrm{FAO}$, Organização das $\mathrm{Na}$ ções Unidas para a Alimentação e Nutrição e da própria OMS - é outra importante referência no campo da regulação do comércio internacional. Comparamos os objetivos dos documentos citados: ${ }^{(29)}$

\begin{tabular}{|c|c|c|}
\hline $\begin{array}{l}\text { Reg. San. Int. } \\
\text { (OMS) }\end{array}$ & $\begin{array}{l}\text { Med. San. Fitossan. } \\
\text { (OMC) }\end{array}$ & $\begin{array}{c}\text { Codex Alimentarius } \\
\text { (FAO \& OMS) }\end{array}$ \\
\hline $\begin{array}{l}\text { Assegurar segurança } \\
\text { máxima contra a pro- } \\
\text { liferação de doenças, } \\
\text { com mínima interfe- } \\
\text { rência no trânsito mun- } \\
\text { dial. }\end{array}$ & $\begin{array}{l}\text { Governos podem adotar } \\
\text { medidas sanitárias, mas } \\
\text { apenas na extensão ne- } \\
\text { cessária para proteger a } \\
\text { saúde, nunca com finali- } \\
\text { dades protecionistas. }\end{array}$ & $\begin{array}{l}\text { Estabelocer padrōes pa- } \\
\text { ra alimentos com foco na } \\
\text { proteção do consumidor } \\
\text { contra alimentos sem se- } \\
\text { gurança práticas frau- } \\
\text { dulentas. }\end{array}$ \\
\hline
\end{tabular}

Os três documentos são enfáticos quanto ao principio de facilitar e reduzir interferências no livre comércio. O Regulamento Sanitário é o ünico que tem aplicação descrita em casos de eventos urgentes de importância internacional, com respaldo na direção geral da Assembléia Mundial de Saúde.

O CDC, de Atlanta, preocupado com a ocorrência de doenças em embarcações de passageiros que operam nos portos americanos, especialmente os surtos de diarréias, desenvolve programa de inspeções desde $1975,{ }^{\{30 / 31\}}$ que, embora baseado na cooperação com os operadores de

(28) World Health Organization, Weekly Epidemiological Record, n. 25, 1999, pp. 193-201.

(29) World Health Organization, Weekly Epidemiological..., cit., n. 25, pp. 193-201.

(30) CDC. Vessel Sanitation Program. (Brochure) Centers for Disease Control and Prevention, Atlanta, Georgia, August 1993. Interrompido em 1986, reformulado e retomado em 1988. National Center for Environmental Health, 1992. Program Summary. Centers for Disease Control, Atlanta, Georgia, 1993. pp. 77-79.

(31) Interrompido em 1986, reformulado e retomado em 1988. National Center for Environmental Health, 1992. Program Summary. Centers for Disease Control, Atlanta, Georgia, 1993, pp. 77-79. 
navios, resguarda a possibilidade de adoção de medidas com base na legislação do país para impedir a introdução ou disseminação de doenças infecciosas. ${ }^{(32)}$ Tal programa, com o apoio da Guarda Costeira, chegou a suspender a partida de cinco navios devido a suas condições sanitárias. $O$ programa ganhou grande visibilidade há alguns anos, quando foi chamado a investigar um surto de infecção por Legionella sp. ocorrido no navio de cruzeiro Horizon. ${ }^{(33)}$

Muitos dos dispositivos internacionais que tratam da regulamentação do trabalho também têm implicações diretas em saúde. São temas de convênios e recomendações adotados pelas Conferências Internacionais do Trabalho. ${ }^{(34)}$ Ao contrário do que ocorre no campo do direito sanitário, as convenções só entram em vigor em caso de ratificação expressa por um determinado número de paises, devendo ser levadas ao Poder Legislativo e, uma vez aprovadas, ao Executivo para ratificação. ${ }^{(35)}$

Algumas das Conferências Internacionais do Trabalho são denominadas marítimas por tratarem especificamente do trabalho no mar. Conforme o quadro de ratificações aos convênios, apresentado em 1987, o Brasil havia ratificado dez deles, número bastante inferior aos dos países europeus (França: 28, Itália e Espanha: 24, Bélgica, Bulgária e Países Baixos: 20) mas dentro da média mundial. Em 1992, o Brasil internalizou a Convenção n. 147 da OIT, um importante instrumento para o controle das condiçōes de saúde e trabalho a bordo, vindo a regulamentar sua aplicação em 1999. ${ }^{(36)(37)}$ Esta Convenção foi ratificada por 40 países $^{(38)}$ e a temática é retomada na Convenção 178 , de $1996^{(39)}$, ratificada até o momento por apenas três paí$\operatorname{ses}^{(40)}$.

(32) "Section 361(a) of the Public Health Service Act", apud Testimony of Richard J. Jackson Director, National Center for Environmental Health Centers for Disease Control and Prevention U.S. Public Health ServiceHouse Committee on Merchant Marine And Fisheries Subcommittees on Merchant Marine and Coast Guard and Navigation. September 28, 1994. Disponivel na rede internet em: http://www.cdc.gov/nceh/programs/sanit/vsp/desc/vsptes.htm

(33) "Section 361 (a) of the Public Health Service Act", cit., September 28, 1994. Disponivel na rede internet em: http://www.cdc.gov/nceh/programs/sanit/vsp/desc/vsptes.htm

(34) Constituiçāo da Organizaçāo Internacional do Trabalho, art. 19, parágrafos $1^{2}$ e $2^{9}$. ApudMELLO, C. D. A., "Curso de Direito...", cit.

(35) MELLO, C. D. A. "Curso de Direito...", cit., pp. 250-251, 550-551.

(36) Ministério do Trabalho, Portaria n. 210, de 30 de abril de 1999. Dispõe sobre a fiscalização das normas de proteção ao trabalho e de vida a bordo prescritas na Convenção n. 147 da OIT, sobre Normas Minimas da Marinha Mercante, promulgada pelo Decreto n. 447, de 7 de fevereiro de 1992. (37) Ratificada pelo Brasil em 17 de janeiro de 1991.

(38) Organização Internacional do Trabalho. Quadro de Ratificaçōes da Convenção n. 147, disponivel via rede internet em: http://ilolex.ilo.ch:1567/scripts/ratifce.pl?C147

(39) International Labour Organization Conference: 84 , in ILOLEX: the ILO's database on International Labour Standards, disponivel na rede internet em: http://ilolex.ilo.ch:1567/public/english/docs/ convdisp.htm

(40) Ainda não vigora; ratificada por Finlândia, Irlanda e Noruega até setembro de 1999. Organização Internacional do Trabalho. Quadro de Ratificaçōes da Convenção n. 178, disponivel via rede internet em: http://ilolex.ilo.ch:1567/scripts/ratifce.pl?C178 
O número de ratificações, no entanto, não parece traduzir fielmente a realidade do trabalho nas embarcações, uma vez que alguns países cujas bandeiras são adotadas por conveniência, sabidamente menos exigentes no respeito a regulamentos, ratificaram um número alto de convênios ${ }^{(41)}$. Os assumidos pelo Brasil referem-se a normas de proteção ao trabalho e de vida a bordo, como também à capacitação profissional, idade mínima, remuneração e jornada de trabalho do pessoal de bordo. Outros convênios e recomendações tratam das condições de alojamento, alimentação, assistência médica, segurança, acidentes de trabalho e estabilidade de emprego, além de tentativas de contenção do engajamento de trabalhadores em navios de bandeiras estrangeiras. ${ }^{(42)}$

Segundo relatório de inspeções realizadas por 14 países marítimos europeus quanto a condiçōes de trabalho, saúde e segurança em navios com passagem por seus portos no periodo de 1983 a 1985, a maior proporção de problemas foi observada naqueles de paises do terceiro mundo e de pavilhões de complacência. Observamos que há uma preocupação especial da OIT em relação aos navios registrados sob estas bandeiras, mas seus esforços parecem não ter ainda produzido efeitos de maior repercussão. ${ }^{(43)(44)}$

Além do que afeta as áreas da saúde e do trabalho, outros atos e organismos internacionais guardam relação com o tema, dirigidos à proteção do meio-ambiente e às condiçōes de navegação. Vale destacar a Organização Marítima Internacional (do inglês - IMO), antiga Organização Intergovernamental Marítima Consultiva (IMCO). ${ }^{(45)(46)}$ Sua parcela de atuação neste campo é com a segurança para navegação e a poluição por produtos químicos, particularmente por petróleo.

Entre as convenções, apenas a Convenção Internacional para a Prevenção da Poluição por Navios (MARPOL) preocupa-se com os dejetos e o lixo, proibindo, em seu anexo IV, a descarga de esgotos a menos de quatro milhas marítimas da terra mais próxima (a não ser que o navio possua um sistema de tratamento aprovado e funcionante); entre 4 e 12 milhas o esgoto deve ser tratado e desinfectado antes de descarregado, somente podendo ser despejado em sua forma bruta a mais de 12 milhas. No entanto, sendo este anexo de adesão voluntária, 22 entre os 55 países signatários assumi-

(41) Conferencia Internacional del Trabajo, $74^{a}$ Reunión (marítima), Memoria del Director General. Genebra, Oficina Internacional del Trabajo, 1987, pp. 101-105.

(42) Organizacion Internacional del Trabajo. Convenios y Recomendaciones Internacionales del Trabajo. Genebra, Oficina Internacional del Trabajo, 1985, pp. 341-1510.

(43) Conferencia Internacional del Trabajo, 74" Reunión, Memoria del Director General, cit., pp. 35-39. (44) Conferencia Internacional del Trabajo, $62^{\circ}$ Reunión (maritima). Navios en que prevalecen condiciones inferiores a las normas minimas, especialmente los registrados bajo banderas de conveniencia. Genebra, Oficina Internacional del Trabajo, 1976, pp. 41-53.

(45) MELLO, C. D. A. "Curso do Direito...", cit., p. 559

(46) "Prevention and Control of Marine Pollution and Liability for Pollution Damage", in The Times Atlas and Encyclopaedia of The Sea. Londres: Times Books Limited, 1989, p. 244. 
ram apenas os anexos que tratam de poluição por produtos químicos e petróleo, entre os quais o Brasil. ${ }^{(47)}$

Podemos observar que as competências e responsabilidades variam conforme se considere a questão como controle de fronteira, regulamentação do trabalho, segurança de navegação, preservação do meio ambiente ou vigilância sanitária, esta última relacionada em vários aspectos às anteriores. No Brasil os controles do poder público sobre a atividade portuária, aeroportuária e de fronteiras são tratados como de responsabilidade exclusiva do poder federal, distribuída entre diferentes órgãos, com seus respectivos poderes de polícia ${ }^{(48)}$.

Internamente, as legislações que regulamentam tal atividade são de diversas naturezas, e em alguns casos conflitantes quanto às exigências e à definição das autoridades competentes. A Constituição de $1988^{(49)}$ determina, por um lado, como competência da União (art. 21, XXII) "executar os serviços de polícia marítima, aérea e de fronteira", por outro, como competência comum da Uniāo, dos Estados, do Distrito Federal e dos Municípios (art. 23, II) "cuidar da saúde e assistência pública, da proteção e garantia das pessoas portadoras de deficiência"; e (VI) "proteger o meio ambiente e combater a poluição em qualquer de suas formas". Ainda, em seu art. 200, define como competência do Sistema Único de Saúde (II) "executar as ações de vigilância sanitária e epidemiológica, bem como as de saúde do trabalhador", e, por fim, em seu art. 225 (V) "controlar a produção, a comercialização e o emprego de técnicas, métodos e substâncias que comportem risco para a vida, a qualidade de vida e o meio ambiente"(50).

Merecem discussão mais cuidadosa outros aspectos não explorados aqui em protundidade.

A organização de blocos comerciais, reunindo vários países, com características sociais, econômicas, culturais e epidemiológicas diversas, gera novos desafios para a construção de acordos bilaterais ou multilaterais que levem em conta a proteção da saúde. O Brasil, em sua articulação com os países do MERCOSUL, tem participado de tratativas que buscam a harmonização de conceitos e dispositivos legais para o fluxo de produtos, tecnologias e pessoas.

A velocidade dos meios de transporte e a quantidade de viagens de longa distância praticamente transformaram o mundo em um ambiente biológico único e extremamente heterogêneo. Pode-se falar, simbolicamente, em uma "gigalópole" mundial, quando bilhões de pessoas estão em contato, conectadas por rotas que atingem os pontos mais remotos.

(47) "Prevention and Control...", cit., p. 244.

(48) Ministérios da Infra-Estrutura, da Marinha, da Agricultura, da Saúde, da Justiça e seus órgãos respectivos, além de outros.

(49) Constituição da República Federativa do Brasil. São Paulo: Saraiva, 1989.

(50) Constituição da República Federativa do Brasil, cit. 
Tamanha dimensão e tal complexidade sugerem a possibilidade de importantes alterações na ocorrência de doenças e desafios inusitados para a epidemiologia. Não é possivel falar em erradicação segura e permanente de qualquer doença transmissivel enquanto não for total, pois enquanto houver possibilidade de nova exposição a partir do contato com grupos humanos isolados, reservatórios animais, laboratoriais ou mesmo virtuais (referimo-nos aqui à possibilidade de "fabricação" de agentes biológicos com diversas finalidades, entre elas a bélica).

A prestigiosa revista The Lancet, em recente editorial, expressa a incerteza quanto à própria varíola, referindo-se à convicção de alguns especialistas de que a volta do vírus, acidental ou intencional, pode ser apenas questão de tempo. (51) Com os estoques mundiais atuais estimados em não mais do que 50 milhões de doses, nenhum pais teria atualmente vacinas suficientes para proteger sua população em caso de epidemia. ${ }^{(52)}$

Ao discutir as causas da emergência de doenças, Hall constrói um quadro em que discrimina, entre os grupos de fatores, o incremento do contato entre humanos e hospedeiros, as viagens (de pessoas, veículos ou vetores) e mudanças no comportamento humano. ${ }^{(53)}$

O surgimento e as notícias, cada vez mais freqüentes, de doenças infecciosas com grande potencial de disseminação e gravidade realça a necessidade de rever-se o enfoque dado à segurança sanitária. Sobressai a importância de sistemas de informação e comunicação ágeis, confiáveis e acessiveis, baseados em sistemas nacionais responsáveis pela vigilância da saúde que ostentem estas mesmas qualidades.

Produtos hoje integram um imenso mercado global, oriundos de fábricas que recebem matérias-primas das mais diversas origens. Nesse contexto, o nexo entre doença e fonte de contaminação não é mais possivel pela intuição; organismos responsáveis pela saúde pública precisam conhecer em profundidade os processos produtivos, as tecnologias e o funcionamento da economia mundial. Os países ditos "em desenvolvimento" abrigam situações sanitárias explosivas, cujo combustivel é a precariedade das condições de vida e das políticas sociais.

Referindo-nos apenas às doenças preveníveis por vacinação, aliamonos às preocupações de Shann e Steinhoff ${ }^{(54)}$, quando alertam para a diminuição da capacidade dos países em desenvolvimento para comprar vacinas e a menor disposição dos países ricos em ajudá-los (a ajuda caiu de US $\$ 63$ bilhões, em 1990, para US\$ 49 bilhões, em 1997). Apontam que

\footnotetext{
(51) “Is Smallpox History?", (Editorial) Lancet, 1999, 353 (9164): 1539.

(52) Ibidem.

(53) HALL, A. J. "Contagion or miasma - is this a communicable disease?" In FINE, P. E. M. (org.) Epidemiology and Control of Communicable Diseases. Londres. 1998 (Apostila do Curso de Pósgraduação da London School of Hygiene and Tropical Medicine). Ver quadro da página seguinte. (54) SHANN, F. e STEINHOFF, M. C. "Vaccines for children in rich and poor countries". Paediatrics, Lancet, 1999, 354 (suppl II), pp. 7-11.
} 
muitos anos após a disponibilização de vacinas básicas nos EEUU, a cobertura nos paises de mais baixa renda per capita ainda era ínfima ${ }^{(55)}$.

Assim, é inevitável a reflexão de que a grande ameaça sanitária é a iniqüidade social entre os povos dos diversos países e entre as classes dentro de cada um. O uso de instrumentos regulatórios como os abordados aqui ou sistemas de vigilância aperfeiçoadíssimos são insuficientes para enfrentá-la. Os regulamentos e demais instrumentos internacionais atuais são produto de políticas econômicas que sequer resvalam nessas preocupações, mas este parece ser um momento em que há maior sensibilidade dos organismos internacionais, abrindo uma expectativa de mudanças mais consistentes e duradouras. Talvez, tomando o exemplo de posições defendidas por iniciativas como a ATTAC, ${ }^{(56)}$ o foco devesse ser outro, assumindo que os fluxos de maior importância para o controle da disseminação de doenças não são os de pessoas, meios de transporte e comércio, mas os de emprego, tecnologia, capitais e lucros.

Finalizamos tomando um trecho de discurso do presidente do Banco Mundial, proferido em seu encontro anual de 1999, e que afirma a identidade de preocupaçōes com o Fundo Monetário Internacional: "Iremos, finalmente, reconhecer que nós vivemos em um só mundo? Olhem ao redor. Estamos conectados por sistemas financeiros, estamos conectados pelas comunicações... estamos conectados pelo meio ambiente, estamos conectados pelo comércio. Imigração não conhece fronteiras, o crime não conhece fronteiras, drogas, guerra e paz não conhecem fronteiras. Somente recursos financeiros nacionais param logo antes das fronteiras...". ${ }^{(57)}$

Causas de emergência de algumas doenças infecciosas ${ }^{(58)}$

\begin{tabular}{|l|l|}
\hline \multicolumn{1}{|c|}{ Causa da emergência } & \multicolumn{1}{c|}{ Exemplos } \\
\hline $\begin{array}{l}\text { Reconhecimento de novos agentes } \\
\text { (novas técnicas de virologia) }\end{array}$ & $\begin{array}{l}\text { Hepatites C e E } \\
\text { Herpesvírus humano 6 (roseola infantum) } \\
\text { Papilomavírus humano } \\
\text { Parvovírus humano B 19 (eritema } \\
\text { infeccioso) }\end{array}$ \\
\hline
\end{tabular}

(55) Entendidos como aqueles de renda per capita inferior a US\$725. SHANN, F. e STEINHOFF M. C. "Vaccines for children...", cit.

(56) ATTAC é a sigla de Ação pela Tributação das Transaçōes Financeiras e Apoio aos Cidadāos, movimento iniciado na França, em torno de um programa que reuniu cidadãos, associações, sindicatos e jornais, inspirado no PLANO TOBIN, tese do economista e prêmio Nobel James Tobin, que propōe normas para a taxação do capital internacional especulativo e o perdāo da divida externa dos paises mais pobres. Textos disponiveis na rede internet em: http://www.attac.org/brasil/visita.htm

(57) Traduzido do discurso de James D. Wolfensohn, Presidente do Banco Mundial, no encontro anual de 1999, Coalitions for Change, Address to the Board of Governors. Washington, D. C., September 28, 1999.

(58) Traduzido de HALL, A. J. "Contagion or miasma - is this a communicable disease?", cit. 


\begin{tabular}{|c|c|}
\hline Causa da emergência & Exemplos \\
\hline $\begin{array}{l}\text { Melhoria no reconhecimento de } \\
\text { doenças }\end{array}$ & $\begin{array}{l}\text { Helicobacter pylori (gastrite, } \\
\text { possivelmente câncer gástrico) } \\
\text { Listeria monocytogenes } \\
\text { Campylobacter jejuni }\end{array}$ \\
\hline $\begin{array}{l}\text { Maior contato entre humanos e } \\
\text { hospedeiros (relacionado ao } \\
\text { desenvolvimento econômico, uso da } \\
\text { terra, programas de reflorestamento, } \\
\text { construção de diques, urbanização, } \\
\text { animais domésticos e outras } \\
\text { mudanças) }\end{array}$ & $\begin{array}{l}\text { Borrelia burgdonferi (doença de Lyme) } \\
\text { Febre hemorrágica do Congo e Criméia } \\
\text { Dengue } \\
\text { Encefalite japonesa } \\
\text { Virus dos grupos LaCrosse e Califórnia } \\
\text { Febre de Lassa } \\
\text { Babesia (febre, anemia hemolítica) } \\
\text { Toxoplasma gondii } \\
\end{array}$ \\
\hline Imunossupressāo & $\begin{array}{l}\text { Aeromonas sp.; Pneumocystis carinii } \\
\text { Cryptococcus sp.; Cryptosporidium; } \\
\text { Microsporidia } \\
\text { Strongyloidis stercoralis } \\
\text { Toxoplasma gondii } \\
\end{array}$ \\
\hline $\begin{array}{l}\text { Aumento na virulência, por mutação } \\
\text { por exemplo }\end{array}$ & $\begin{array}{l}\text { Haemophilus influenzae biogrupo } \\
\text { aegyptius (febre purpúrica do Brasil) } \\
\text { Streptococcus grupo A (choque tóxico, } \\
\text { febre reumática) }\end{array}$ \\
\hline $\begin{array}{l}\text { Desenvolvimento provável de novos } \\
\text { patógenos }\end{array}$ & $\begin{array}{l}\text { Echerichia coli } 0157: H 7 \text { (colite } \\
\text { hemorrágica, síndrome hemolítico- } \\
\text { urêmica) } \\
\text { V. Cholerae } 0139\end{array}$ \\
\hline $\begin{array}{l}\text { Viagens (de pessoas, de veículos ou } \\
\text { vetores, por exemplo, importação de } \\
\text { Aedes albopictus para os EEUU em } \\
\text { pneus vindos da Asia; disseminação } \\
\text { de cólera na América Latina em água } \\
\text { de lastro de navios) }\end{array}$ & $\begin{array}{l}\text { Epidemia por Vibrio cholerae nas } \\
\text { Américas } \\
\text { Febre do Vale do Rift e encefalite eqüina } \\
\text { venezuelana (importação de mosquitos } \\
\text { e/ou animais infectados) }\end{array}$ \\
\hline $\begin{array}{l}\text { Mudanças do comportamento humano } \\
\text { (p.e. comportamento sexual, dieta) }\end{array}$ & $\begin{array}{l}\text { Chlamydia trachomatis } \\
\text { HIV } 1 \text { e } 2 \\
\text { Anisakis (dor abdominal e vômitos): } \\
\text { associada à ingestāo de peixe cru }\end{array}$ \\
\hline
\end{tabular}

